\title{
The role of ultrasound in diagnosis of obstructive Jaundice causes in Sudanese population
}

\author{
Moawia Gamersddin ${ }^{1,2}$,Rasha Abdalgaffar ${ }^{2}$, Mohamed yousef ${ }^{3,4}$ \\ ${ }^{I}$ Taibah University, College of Medical Applied Sciences, Department of Diagnostic Radiologic Technology, \\ Fax: 8475790 P.O: 30001 Almadinah Almunawwarah, KSA \\ ${ }^{2}$ Alzaeim Alazhari University, Faculty of Radiological Sceinces and Medical Imaging.P.O.Box1432 Khartoum \\ Bahri 13311-Sudan \\ ${ }^{3}$ College of Medical Radiologic Science, Sudan University of Science and Technology. P.O.Box 1908, \\ Khartoum, Sudan \\ ${ }^{4}$ Radiologic technology department, college of applied medical science , Qassim university, Buraduh, KSA .
}

\begin{abstract}
This study was done to assess the role of ultrasound in diagnosis ofobstructive jaundicecauses. The study took place in different Khartoum clinical centers and hospitals in the period between Jan 2010 - March 2011.A total of 102 patients were examined using ultrasound(U/S), $3.5 \mathrm{MHz}$ probe, Fukuda, Toshiba, Sheimadzu and Aloka Machine. The population of the study(jaundiced patients)had been selected by the technique of non-probability sampling and full history was taken.The causes of obstructive jaundice were detected as stone $19 \%$., mass $51 \%$, Sensitivity of ultrasound in determining the level of obstruction was $96 \%$ and extra hepatic obstruction was $67 \%$. The prevalence ofobstructive jaundice was found to behigher in females (58\%) than male (42\%).Ascites and liver cirrhosis were found in $24 \%$ of the patients, hepatitis and hepatomegaly represent $33 \%$. The study confirmed that obstructive jaundice represent $89.2 \%$ of the patients and non- obstructive jaundice was 10.8\%.The study recommended to measure bile duct, liver size, portal vein, spleen and compare the liver echo texture with the adjacent organs. Scanning should be performedfor liver metastasis and also detect stone in the common bile duct.
\end{abstract}

Key words: Ultrasound, obstructive jaundice, ascites, Liver disease,non-obstructive jaundice, Sudanese patients

\section{Introduction:}

Jaundice is a condition produced when excess amount of bilirubin circulating in the blood stream dissolve in the subcutaneous fat, causing a yellowish appearance of the skin and the eyes. All other jaundice indicates overload or damage to the liver, or inability to more bilirubin from liver through the biliary tract to the gut. There are two types of jaundice (non-obstructive and obstructive jaundice) ${ }^{[1]}$. Obstructive jaundice caused by obstruction of the bile duct, as with gallstones and masses. The liver normally produces about 1 liter of bile each day, which is secreted (passed) into the bile duct empties into the upper intestine to help in digestion. Obstruction anywhere causes the blood levels of bilirubin to increase resulting in obstructive jaundice ${ }^{[2]}$. The most common causes of non-obstructive jaundice are alcoholic liver disease ${ }^{[3]}$. There was other investigations which helped in diagnosis of jaundice such as serum bilirubin, hepatic enzyme, complete blood account, liver biopsy and urine general. Also radiological investigations answering clinical questions and careful review of localizing solid mass, so that ultrasound cover as superior diagnostic tool in patient with obstructive jaundice ${ }^{(4)}$. Recent years have witnessed a rapid and continuous evolution in the diagnosis of biliary obstructive disease. Totraditional methodologies, such as US (ultrasonography),(CT (computed tomography), ERCP (endoscopic retrograde cholangiopancreatography) and PTC (percutaneous transhepatic cholangiography), there have been added MRCP (magnetic resonance cholagiopancreatography) and CCTcholangio computed tomography), which have prompted a comprehensive review of the whole diagnostic imaging procedure ${ }^{[5-12]}$.Ultrasound has been always considered the first choice technique in the study of biliary obstructive disease, due to its accessibility, speed, ease of performance and low cost ${ }^{[13,14]}$. Thishas been even more so in recent years, following the technological evolution of US equipment which, thanks to Tissue Harmonic Imaging (THI), gives better visualization of fluid-filled structures (such as the biliary structures), reduced artifacts, and enhanced contrast resolution ${ }^{[15,16]}$.ERCP has been considered the gold standard of biliary structureimaging since its introduction in 1970, and is currentlymaintaining its therapeutic application. ${ }^{[17-21]}$

\section{Material and methods:}

This is descriptive study deal with role of ultrasound in diagnosis and determines thecauses of obstructive jaundice in different hospitals, clinics and diagnostic centers in Khartoum State. There were 102 caseshad been selected with the technique of non- probability sampling, each patient scanned by an international 
scanning guidelines and protocols, by qualified sonologist. Data had been collected using the data collection sheet and analyzed by using computerized programme.

\section{Results:}

The general characteristics of the sample studied:The majority of patients studied were females $(58 \%)$, while males present the percent of $(42 \%)$, Table (1) shows that most of affected patients of the age ranged between $45-75$ years old.

Table (1): Age (year) frequency distribution:

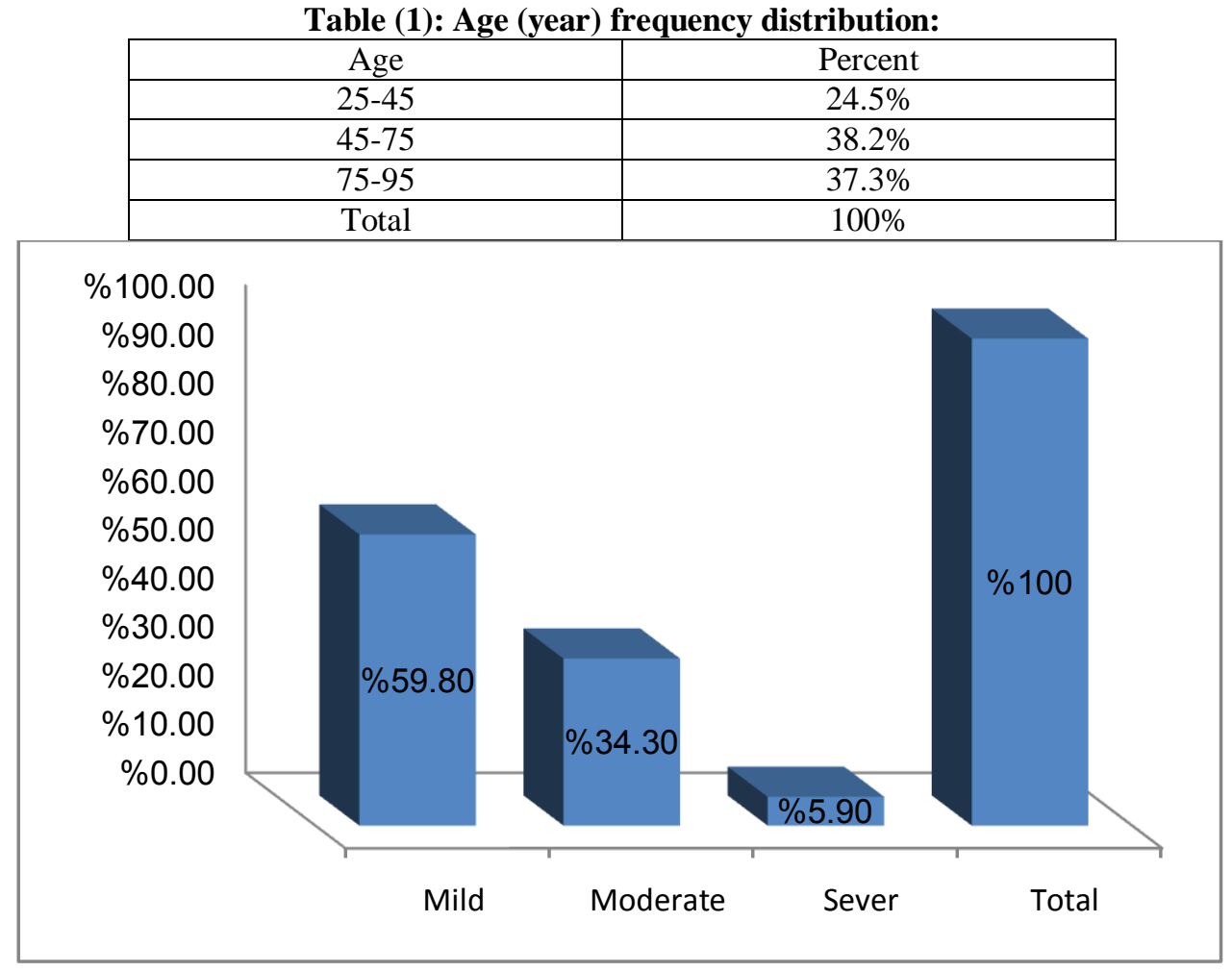

Figure (1) Yellowish color frequency distribution:

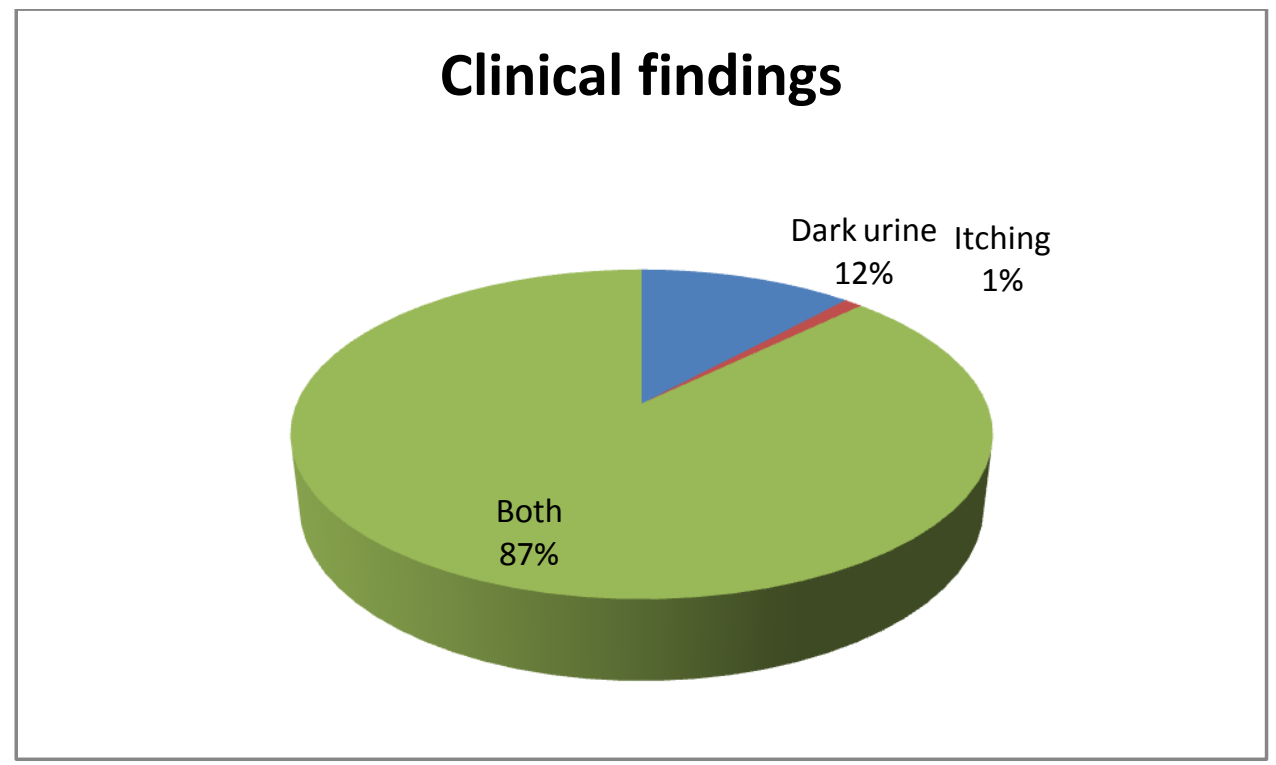

Figure (2) Clinical findings frequency distribution: 


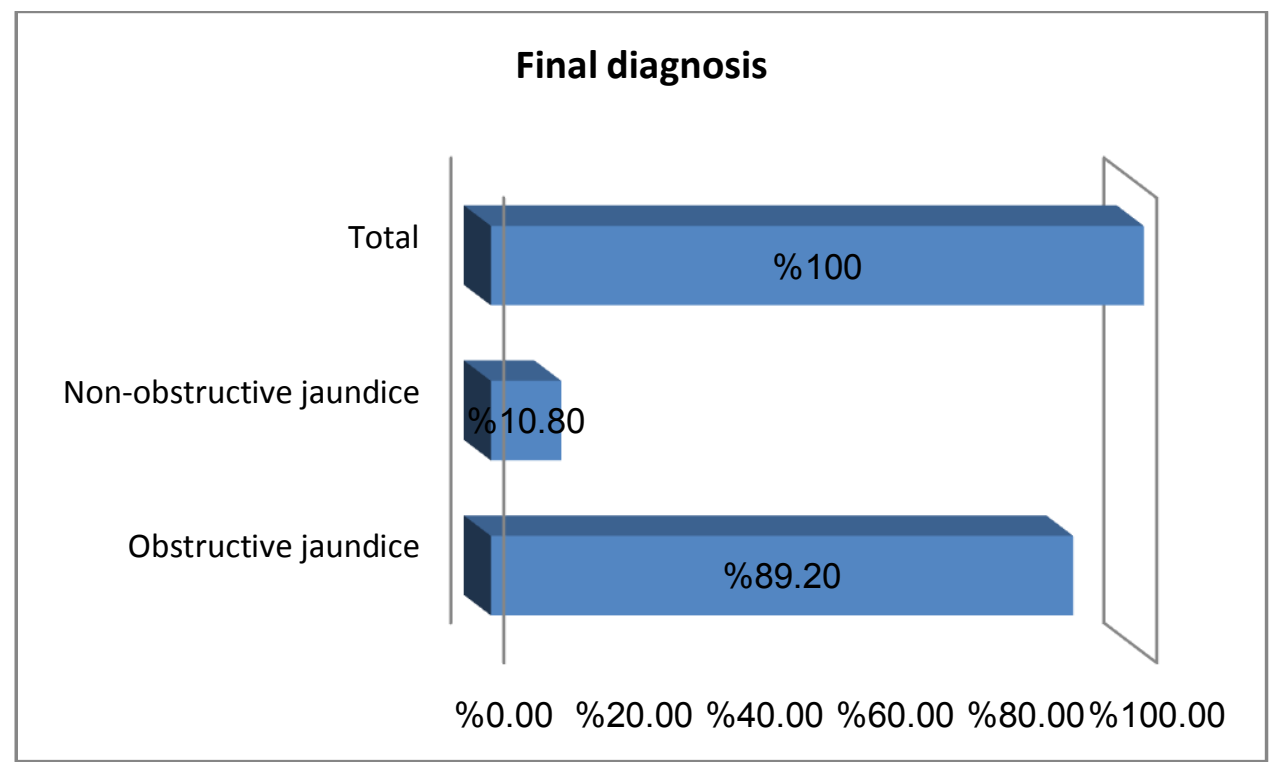

Figure (3): Final diagnosis frequency distribution:

Table (2): Relation between cause of obstruction and age group:

\begin{tabular}{|l|c|c|c|l|}
\hline & \multicolumn{3}{|c|}{ Age } & \\
\hline $\begin{array}{l}\text { Cause of } \\
\text { obstruction }\end{array}$ & $25-45$ & $45-65$ & $65-85$ & Total \\
\hline Stone & 6 & 8 & 6 & 20 \\
& $5.9 \%$ & $7.8 \%$ & $5.9 \%$ & $19.6 \%$ \\
\hline Mass & 8 & 21 & 23 & 52 \\
& $7.8 \%$ & $20.6 \%$ & $22.4 \%$ & $51 \%$ \\
\hline Other & 11 & 10 & 9 & 30 \\
& $10.8 \%$ & $9.8 \%$ & $8.8 \%$ & $29.4 \%$ \\
\hline Total & 25 & 39 & 38 & 102 \\
& $24.5 \%$ & $38.2 \%$ & $37.5 \%$ & $100 \%$ \\
\hline
\end{tabular}

\section{Discussion}

Table (1) shows that most of affected patients of the age above45years old $75.5 \%$, because most patientsat this age had a previous history of alcohol abusing and schestosomiasis and most female affected by gallbladder stone at age above 40 years

The study showed that the incidence of juandice increase in female more than male, $58 \%$ of female and $42 \%$ of male, because female exposed to the drugs like contraceptive device which lead to gallbladder stone, also recurrent pregnancy decrease immunity of female and became more prone to infection.Figure (1) showed that most of the patients had mild yellowish color 59\% and Figure (2) shows $11.8 \%$ of patients had dark urine.In this study $28.2 \%$ of patient had painless jaundicebecause most of these patients had been affected with Ca- head of pancreas.Most of the mass appeared as single nodule and represent $94 \%$.There was $25 \%$ of the patientscomplicated withascites.Table (2) and Figure (3) Showed that obstructive jaundice is mainly caused by masses such as (Ca- head of pancreas) which represent $51 \%$ and the stone represent $19 \%$, because the Ca head of pancreas blocked the area of the Ampulla of Vater and distal area of common bile duct thus preventing bile to enter the gallbladder. It was observed that most the level of obstruction was extra hepatic( 96\%) and the intrahepatic obstruction was $67.1 \%$ of the jaundiced patients. There was strong relation between age and causes of obstructive jaundice. The study revealed that the incidence of mass of the head of pancreas increased with advanced age due to decrease of immune and catching of inflammatory diseases. This study showed that the liver with normal parenchyma was $60 \%$ and $40 \%$ showed changing in the liver parenchyma such as (cirrhosis, hepatitis with change echogenicity of the liver).

\section{Conclusion:}

The study approved that ultrasound provided significant information about the gallbladder and the biliary ducts and usually differentiate between obstructive jaundice and non-obstructive jaundice, stones. Ultrasound is sensitive in detection of any liver parenchymal changes, also a useful tool to detect any change in gallbladder wall, stones impacted in the common bile duct, tumor of the head of pancreas In jaundiced patients, 
ultrasound can detect single nodular masses or any inflammatory changes and also assessesliver size. This study showed that elderly patients more affected and the female affected more than male.

\section{References:}

[1]. http://gutbmg.com A (8-12-2010/8pm

[2]. http://www. causesand symptoms of jaundice, digesti $(12-1-20100-8 \mathrm{pm})$.

[3]. http:///.digestionhelp.orgjaundice $\operatorname{Htm}(1-2-2011-8 \mathrm{pm})$

[4]. C.S. sinnataby. Last's anatomy, regional and applied, 10th ed. 1999, chapter five.

[5]. Sackmann M, Beuers U, Helmberger T: Biliary imaging: magneticresonance cholangiography versus endoscopic retrogade cholangiography.J Hepatol, 1999; 30: 334-38

[6]. Zhi FC, Yan ZQ, Li XL et al: Prospective study of diagnostic valueof magnetic resonance cholangiopancreatography versus endoscopicretrograde cholangiopancreatography in cholangiopancreatic diseases.Chinese Journal of Digestive Diseases, 2002; 3: 124-32

[7]. Macdonald GA, Peduto AJ: Magnetic resonance imaging and diseasesof the liver and biliary tract. Part 2. Magnetic resonance cholangiographyand angiography and conclusions. J Gastroenterol Hepatol,2000;15: 992-99

[8]. Barish MA, Yucel EK, Ferrucci JT: Magnetic resonance cholangiopancreatography. N Eng1 J Med, 1999; 341: 258-64

[9]. Little AF, Smith PJ, Lee WK et al: Imaging of the normal andabnormal pancreaticobiliary system with single-shot MR cholangiopancreatography: a pictorial review.Australas Radiol, 1999; 43: 427-34

[10]. Lopera JE, Soto JA, Munera F: Malignant hilar and perihilar biliaryobstruction: use of MR cholangiography to define the extent of biliaryductal involvement and plan percutaneous interventions. Radiology, 2001; 220: 90-96

[11]. Motohara T, Semelka RC, Bader TR: MR cholangiopancreatography.Radiol Clin North Am, 2003; 41: 89-96

[12]. Zandrino F, Benzi L, Ferretti ML et al: Multislice CT cholangiography without biliary contrast agent: technique and initial clinical results in the assessment of patients with biliaryobstruction. Eur Radiol,2002;12: 1155-61

[13]. Hakansson K, Ekberg O, Hakansson HO, Leander P: MR andultrasound in screening of patients with suspected biliary tract disease.Acta Radiol, 2002; 43: 80-86PERSONAL USE

[14]. Menu Y, Vuillerme MP: Non-traumatic abdominal emergencies: imagingand interventionin acute biliaryconditions. Eur Radiol, 2002; 12:2397-406

[15]. Ortega D, Burns PN, Hope Simpson D, Wilson SR: Tissue harmonic imaging:is it a benefitfor bile duct sonography? Am J Roentgenol, 2001;176:653-59

[16]. Migaleddu V, Virgilio G, Campisi G et al: Conventional ultrasonographyversus TissueHarmonic Imaging for the assessment of the commonbile duct in cholecystectomized patients. Radiol Med, 2002; 104:52-57

[17]. Lomas DJ, Bearcroft PW, Gimson AE: MR cholangiopancreatography:prospective comparison of a breath-hold 2D projection technique withdiagnostic ERCP. Eur Radiol, 1999; 9: 1411-17

[18]. Arslan A, Geitung JT, Viktil E et al: Pancreaticobiliary diseases.Comparison of 2D single-shot turbo spin-echo MR cholangiopancreatographywith endoscopic retrograde cholangiopancreatography.ActaRadiol,2000; 41: 621-26

[19]. Baron TH, Fleischer DE: Past, present, and future of endoscopic retrogradecholangiopancreatography: perspectives on the National InstitutesOfHealth consensus conference. Mayo Clin Proc, 2002; 77: 407-12

[20]. Yeh TS, Jan YY, Tseng JH et al: Value of magnetic resonance cholangiopancreatographyin demonstrating major bile duct injuries followinglaparoscopiccholecystectomy.Br J Surg, 1999; 86: 181-84ONLY

[21]. Filippone A, Ambrosini R, Fuschi M et al: Clinical impact of MR cholangiopancreatographyin patients with biliarydisease. Radiol Med, 2003;105:27-35 